\title{
As desilusões da crítica de poesia
}

\section{Marcos Siscar}

Resumo: Parte da critica brasileira de poesia expressa com frequểncia um sentimento de insatisfaçảo em relaçáo à produçâo contemporànea, em especifico pelo eniraquecimento dos desafios que essa produçâo se coloca a si mesma. Se é pertinente analisar as questôes que a poesia se coloca, também é sensato analisar a natureza das questôes que a critica tem colocado à poesia. As "ilusōes perdidas" atribuidas a poesia, não deixam de designar o impasse que é enfrentado pela própria escrita critica. Palavras-chave: crise da poesia, poesia contemporanea, critica literíria,

\footnotetext{
Abstract: Part of Brazilian criticism of poetry has frequently expressed a feeling of dissatisfaction towards the contemporaneous production, especially because of the weakening challenges this kind of production has brought to itself. Nevertheless, if it is important to analyze the questions poetry puts to itself, it is also sensible to ask what kind of questions criticism has made in relation to poetry. The "lost delusions of poetry" seem to indicate an impasse which is faced by critical writing itself. Keywords: crisis of poetry, contemporaneous poctry, literary criticism.
} 
Está claro que, ao longo dos anos, tenho desejado ao mesmo tempo conservar e perder, compor um sempre com um nunca, o nunca-mais da perda com o para-sempre da tradição, o que é impossível...

Michel Deguy

\section{A poesia sob suspeita}

Numa entrevista recente, os editores de uma revista, diante da evidência de que se havia publicado pouca poesia brasileira no último número, precisaram responder a uma pergunta incômoda: "os editores [...] estão cismados com a poesia brasileira contemporânea?" Talvez a pergunta devesse ser reformulada, mas a confirmação da cisma pelo entrevistado (também poeta) é significativa. De fato, independentemente do caso específico, existe um mal-estar que se apresenta não apenas como cisma da poesia em relação a si mesma, ${ }^{2}$ mas como desconfiança de quem publica ou interpreta poesia - digamos "a crítica".

A opinião é suficientemente reiterada para soar como habitual. A poesia brasileira teria empobrecido depois do fim das vanguardas, isolando-se em guetos, para perder-se definitivamente no universo sem referência do "pós-utópico". A mercantilização dos espaços de discussão, a midiatização da subjetividade, o espírito de autoelogio, a falta de projeto cultural conviveriam com uma paradoxal vitalidade quantitativa. Embora "profícua", a literatura de nossos dias permanece "à deriva", como resume Fábio de Souza Andrade. ${ }^{3}$ A falta de clareza quanto a seus rumos se refletiria paradoxalmente, mas significativamente, na vitalidade das revistas especializadas, das antologias, na vulgarização do gesto antológico e do artigo de situação - essas que são tentativas de organizar o sentido de um contemporâneo carente de clareza sobre sua própria identidade.

1 LIMA, Ricardo. Entrevista: Régis Bonviccino \& Alcir Pécora. Disponivel em: <http://www.germinaliteratura. com.br/sibilaz2005_ricardolima.htm>. Acesso em: 6 mar. 2006.

MORICONI, Ítalo. A problemática da pós-modernidade na literatura brasileira. Cadernos da ABF, v. III, n. 1. Disponivel em: <http://www.filologia.org.br/abf/volume3/numero1/o8.htm>. Acesso em: 6 mar. 2006.

2 SISCAR, Marcos. A cisma da poesia brasileira. Sibila, v. 8/9, 2005. Disponivel em: <http://www.germinaliteratura. com.br/sibilazo05_acismadapoesia.htm>. Acesso em: 6 mar. 2006.

3 ANDRADE, Fábio de Souza. Crítica literária: que bicho é este?. Folha de S.Paulo, São Paulo, 23 abr. 2005.

112. SISCAR, Marcos. As desilusões da crítica de poesia 
Heloísa Buarque de Hollanda, ao apresentar sua antologia dos anos 1990, Esses poetas, começa exprimindo uma motivação pessoal: "Essa não é a primeira vez. O fato é que, diante de qualquer formação de consenso a respeito de quedas de vitalidade na produção cultural, sinto-me impelida a organizar uma antologia de novos poetas." ${ }^{4}$ Considerando-se que a autora vem lançando antologias há mais de 25 anos, tal seria provavelmente, para ela - a idade desse infeliz consenso sobre nossa pobreza poética. Ressalte-se que tal situação tem sido descrita periodicamente nos trabalhos de Iumna Simon, publicados durante mais ou menos a mesma época. Neles, a autora analisa o quadro mais abrangente da poesia brasileira do fim do século $\mathrm{xx}$ e considera que aquilo que se apresenta como "novo" em poesia manifesta-se, nesse momento, como abandono da historicidade, por meio da identificação da poesia com rótulos editoriais e de sua rendição ao horizonte das trocas reguladas pelo mercado. ${ }^{5}$

Ora, o discurso universitário poucas vezes exprime opinião diferente e as exceções são conhecidas. Célia Pedrosa e Maria Lúcia de Barros Camargo, por exemplo, constatam que existe "uma revigoração bastante forte no campo da poesia"' desde a década de 1990, com incremento de produção de qualidade, boa recepção crítica, variedade de revistas literárias. Ítalo Moriconi? aponta, mais enfaticamente, os anos de 1990 como ocasião do "surgimento de uma nova e brilhante geração de poetas", favorecida pela reconfiguração do campo institucional e cultural brasileiro. Embora conte com alguns defensores, esta não parece ser uma tese corrente sobre o estado atual da poesia, não pelo menos do modo enfático como se manifesta o topos da crise do gênero poético na crítica universitária e, frequentemente, por outros motivos, no jornalismo.

4 HOLLANDA, Heloísa Buarque de. Esses poetas: uma antologia dos anos 9o. Rio de Janeiro: Aeroplano, 1998, p. 9.

5 SIMON, Iumna. Considerações sobre a poesia brasileira em fim de século. Novos Estudos. São Paulo: Cebrap, V. 55, P. 27-36, 1999.

6 PEDROSA, Célia; CAMARGO, Maria Lúcia de Barros (org.). Poesia e contemporaneidade: leituras do presente Chapecó: Argos, 2001, p. 7.

7 MORICONI, Ítalo. A problemática da pós-modernidade na literatura brasileira. Cadernos da ABF, v. III, n. 1 Disponivel em: <http://www.filologia.org.br/abf/volume3/numero1/o8.htm>. Acesso em: 6 mar. 2006.

8 "Os anos 80 são importantes como o contexto que explica o surgimento de uma nova e brilhante geração de poetas nos anos 90 . No arco que une e desune os anos 70 e 90, vemos uma trajetória que levou da contracultura à reação cultural. Com a saída de cena do socialismo real soviético, o neoconservadorismo e o neoliberalismo polarizaram o debate político. Em cultura, a onda neoconservadora, e o declínio relativo dos apelos transgressores, favoreceu a aproximação, até entāo inédita, entre instituições tradicionais do saber literário, e da poesia a elas ligada, e a instituição universitária. Temos assim uma reconfiguração do campo institucional cultural brasileiro." (MORICONI, Ítalo. A problemática da pós-modernidade na literatura brasileira, op. cit.).

Teresa revista de Literatura Brasileira [10|11]; São Paulo, p. 109-120, 2010. - 113 
Nesse contexto, mesmo a expressão da vitalidade do processo cultural vem respingada pelas tintas da melancolia. É o que faz, por exemplo, Heloísa Buarque de Hollanda, no prefácio em que publica e divulga os poetas dos anos 1990, lamentar o "neoconformismo político-literário" de uma geração para a qual a "apatia" é "o ethos de um momento pós-utópico". Até Augusto de Campos, velho poeta engajado com o "presente do futuro", prefere ver o contemporâneo como uma "fase de transição", uma época de "desencantos", ${ }^{10}$ numa clara desaprovação ao desempenho de seus "herdeiros" A dificuldade que se tem em incorporar as últimas décadas do século $\mathrm{xx}$ a uma narrativa convincente da história literária brasileira é significativa: o desinteresse pela poesia do presente - que, em alguns casos, coincide com a incapacidade de lidar com os impasses desse presente - acaba convivendo, a meu ver, de modo preocupante, com um processo de monumentalização pouco sensata dos poetas do passado, em especial os do modernismo.

O mesmo processo de esvaziamento do contemporâneo é reconhecível, inclusive, em análises que pretendem abordar de frente a literatura do presente; a eleição de um único poeta como portador do sentido do contemporâneo (por oposição a ele, justamente) é um procedimento crítico que cria silêncio em torno desse poeta, ao valorizá-lo, que impõe um outro tipo de desqualificação da história literária recente. Embora também seja um procedimento comum na tradição crítica do concretismo, o exemplo mais notório, me parece, é o do tratamento dispensado por Roberto Schwarz ${ }^{11}$ ao poeta Francisco Alvim. ${ }^{12}$

O fim das vanguardas, que Haroldo de Campos ${ }^{13}$ diagnosticou como a época do "poema pós-utópico" (a época constelar por excelência, por assim dizer, do "acaso" tornado história), a julgar por essas recensões, parece constituir-se no discurso da crítica não exatamente como uma convivência harmoniosa (como queria Haroldo), mas como uma apatia demissionista. Num caso como no outro, chama a atenção a

9 HOLLANDA, Heloísa Buarque de. Esses poetas: uma antologia dos anos 90, op. cit., p. 16.

10 CAVALCANTI, Jardel Dias. Entrevista com o poeta Augusto de Campos. Digestivo cultural. Disponível em: <http://www.digestivocultural.com/colunistas/coluna.asp?codigo=993>. Acesso em: 06 mar. 2006.

11 SCHWARZ, Roberto. Orelha para Francisco Alvim. Sequências brasileiras. São Paulo: Companhia das Letras, 1999. Cf. tb. SCHWARZ, Roberto. Elefante complexo. Folha de S.Paulo, São Paulo, 10 fev. 2001.

$12 \mathrm{Na}$ análise da obra de Alvim, o crítico empreende uma vigorosa e contínua "verificação recíproca" não apenas entre "as formas artísticas e a experiência histórica" (Idem, ibidem, ibidem), como também entre o autor e os grandes poetas do modernismo, aos quais se soma a figura totêmica de Machado de Assis.

13 CAMPOS, Haroldo. Poesia e modernidade: da morte da arte à constelação. O poema pós-utópico. O arco-íris branco. Rio de Janeiro: Imago, 1997.

114 - SISCAR, Marcos. As desilusões da critica de poesia 
ideia de que a poesia é pensada em relação a uma utopia, à formulação explícita de um projeto cultural. Poderíamos nos perguntar se o cumprimento dessa exigência, alçado ao primeiro plano apenas recentemente, justamente na época das vanguardas, é a única maneira que a poesia tem de colocar em evidência suas inquietações com seu lugar de origem (com a ideia de homem, de comunidade, de relação com o sensível etc.) É apenas sob a ótica de uma tal exigência que a ausência de utopias poderia manifestar-se como espaço destituído de sentido poético, de reflexão sobre a condição humana (ou, alternativamente, como solução de nossos problemas, "presentidade" redentora dos inconvenientes da história).

A poesia deve dizer a que vem? A poesia deve formular um universo de coerência, uma pedagogia, uma estratégia de ação? É importante lembrar que a relação entre poesia e cultura é extremamente problemática desde pelo menos Baudelaire e tem se manifestado não apenas na forma positiva do projeto, mas na forma problemática do tédio, da alienação, da violência, do sacrifício, do mistério, sem com isso carecer de sentido.

\section{O desencanto}

Retomo uma resenha de Silviano Santiago, publicada em 2001 por ocasião do lançamento de um livro de Carlito Azevedo. Embora contenha qualificações inequívocas a respeito da excelência do poeta, a resenha tem por título e por tema "As ilusões perdidas da poesia". Trata-se de um texto delicado, costurando na ambiguidade da argumentação a estima e o desencanto. $O$ texto realiza habilmente a difícil tarefa de articular a importância do poeta à falta de ambição da poesia. Assim, o poeta se torna "o aguardado poeta pós-cabralino" em um contexto paradoxalmente "melancólico", "finissecular" de uma poesia que agoniza. O tema do "cotidiano" aparece, aí, como traço da poesia contemporânea, discurso sem efeito dentro de um quadro cultural muito mais complexo: "Nada existe de mais opaco à razão contemporânea do que o cotidiano dos ovos estrelados". Nosso conhecimento sobre o discurso já sabe tratar a simplicidade como uma estratégia retórica e, além disso, é preciso reconhecer que tem cabido à ciência positiva e às humanidades mais prestigiadas a tarefa de dar sentido às grandes questões da vida:

A vida enquanto conceito e abstração é hoje objeto da nova gramática e sintaxe - 0 genoma - a que chegam os cientistas nos laboratórios de pesquisa. Para que a literatura? A história com suas coordenadas de calendário religioso e leigo, associada à confusa 
geografia com suas sangrentas cartografias e reterritorializações pós-coloniais, bandeia para o lado dos filósofos, cientistas sociais, jornalistas e políticos.

Só sobra para o artista o opaco e enigmático dia a dia de sua vida. ${ }^{14}$

Sobra para o poeta "recobrir de palavras os eventos insignificantemente significativos do cotidiano." ${ }^{15} \mathrm{O}$ diagnóstico é terrível e não podemos senão levá-lo a sério, ainda que o contexto da resenha o formule em paralelo com a análise de uma "poderosa" obra poética, que coloca o objeto lírico como "luxuosa fantasia na passarela da imaginação do leitor" Em todo caso, alijada do sentido abstrato e material da vida, excluída das discussões filosófico-religiosas e geopolíticas, a poesia aliena-se dos rumos da cultura. Seu papel é diminuído, na medida em que deixa de colocar as grandes questões da existência. O diagnóstico não está distante daquele formulado por Michel Deguy em termos mais abrangentes, sobre a "diminuição" do espaço atribuído ao poético, ${ }^{16}$ sobre sua dificuldade de comover e de interferir, de causar dor. ${ }^{17}$ Mas, diferentemente de Deguy, que reafirma o papel humanista da poesia, disposta à "profanação", à tentativa de tornar o mundo "habitável" a partir do próprio desencanto, a pergunta "para que a literatura?" soa muito mais como uma terrível constatação, ou eventualmente como uma provocação (se lembrarmos que Silviano Santiago é, também, poeta e romancista).

Embora seja dirigida ao contemporâneo, de modo específico e fundamentado, gostaria de lembrar que a suspeita sobre o esgotamento das possibilidades do literário não é exclusiva de nosso tempo. Em 1920, em plena gestação do modernismo, Mário de Andrade falava do "cansaço intelectual" de uma época de tantas novidades; em 1956, no epicentro de formulações teóricas que enriqueceriam a poesia da segunda metade do século xx, Mario Faustino constatava a "agonia" da poesia brasileira. No final do século XIX, os poetas já nomeavam a concorrência do jornalismo, da ciência e até mesmo do romance (a "universal reportagem", como dizia Mallarmé) para expressar a submissão da poesia aos imperativos materiais e à racionalidade aplicada à ordem social, em outras palavras, para elaborar o sentido da marginalidade do poético. Antes de Joyce dar início ao "fim do romance",

14 SANTIAGO, Silviano. As ilusōes perdidas da poesia. Jornal do Brasil, Rio de Janeiro, 15 dez. 2001.

15 Idem, ibidem.

16 DEGUY, Michel. Situação. Inimigo Rumor. Brasil/Portugal: 7 Letras/Cotovia, Angelus Novus, n. 11, 2001, p. 25-31.

17 Idem. De la poésie d'aujourd'hui. In: DEGUY, Michel; DAVREU, Robert; KADDOUR, Hedi. Des poètes français contemporains. Paris: ADPF Publications, 2001.

116. SISCAR, Marcos. As desilusões da crítica de poesia 
Mallarmé já havia nomeado uma "crise" de verso. Antes deles, ainda, Baudelaire lamentava a situação rebaixada da poesia, quando constatava que, em sua época, seria comum o burguês pedir um poeta assado para o jantar, embora todos estranhassem que o poeta quisesse um burguês em seu estábulo. Quero dizer com esses exemplos - colhidos entre alguns dos mais conhecidos - que o discurso da crise, ou seja, do descompasso entre a poesia e as grandes questões da realidade, é um fenômeno da modernidade. Em um primeiro momento, não se trata nem mesmo de decidir se a crise é um fato, se existe ou se não existe crise, mas de constatar que se pode mapear um discurso da crise que coincide, historicamente, com a narrativa da própria modernidade poética. Eu diria que a poesia moderna surge desse sentimento de crise, afirmando-se a partir da crise, como discurso da crise, ou seja, como sentimento do colapso de seu lugar (quer seja o da frase que compõe seu verso, quer seja o da realidade que compõe seu mundo).

Ou seja, historicamente, o que chamamos "poesia moderna" é um discurso que se alimenta da crise para reinventar seu papel dentro da cultura. É pela via do discurso da crise que se justifica ou se torna necessária a reinvenção ou a refundação da subjetividade e da comunidade. Constatar essa historicidade do discurso literário como discurso da crise não invalida nem diminui a necessidade do diagnóstico sobre a situação específica do contemporâneo. Pelo contrário, de certo modo, ela confirma e solicita esse diagnóstico.

Entretanto, derivam também dessa historicidade da crise algumas consequências. Em primeiro lugar, é preciso responder à questão: o que quer dizer, o que tem querido dizer, o que de fato queremos dizer quando dizemos que a poesia experimenta seu lugar como lugar de crise, literariamente, culturalmente? Como a poesia tem feito isso (a partir de Baudelaire, pelo menos, e, desde então, em circuito internacional)? Que tipo de tremores de terra esse sentimento de colapso acarreta? Como se explica que a crise se torne tradição e, paradoxalmente, um modo de existência e de sobrevivência da poesia? Aliás, como distinguir os vários tipos de discurso da crise, que se manifestam tanto no poeta engajado, quanto no poeta beat, no poeta católico ou no poeta fascista? E, ainda, se existem vários tipos de discurso da crise, como definir a experiência literária digna dessa crise na qual depositamos toda a utopia literária da modernidade?

A segunda consequência dessa historicidade da crise - que me interessa, aqui, mais de perto - é que, sendo discurso, ela não existe e não se sustenta sem um sujeito que a enuncie. Esse sujeito é a crítica, é a história, é a teoria literária mesmo quando são exercidas pelos próprios poetas (em ensaios, autobiografias, 
correspondências ou, por que não... em poemas). Embora as dimensões sejam amplas, nunca é demais lembrar que a constatação dessa crise, ou seja, a narrativa da própria "modernidade" (de Baudelaire a Mallarmé ou a Yeats, de Rimbaud às vanguardas, de Mário de Andrade a Drummond, ou de Valéry a João Cabral) tem também uma história e uma teoria cujos pressupostos deveriam ser objeto de estudo, como construção de sentido e não apenas como sequência mais ou menos homogênea de fatos. Em relação ao contemporâneo, a singularidade da enunciação da crise, embora em coerência com a tradição, é composta por um elemento complicador, que quero destacar aqui: o questionamento da situação da própria linguagem crítica.

Se a crise é um discurso histórico-teórico e se ela depende também do sujeito que a enuncia, hoje, uma terceira consequência se impõe: quando um crítico aponta a situação degradada do contemporâneo, ele expressa um interesse ou um desejo de refundação; ele expressa, pelo menos, uma demanda de sentido em um contexto no qual esse sentido parece perdido. $O$ discurso da crise está ligado ao espírito de "decadência", como se dizia no século XIX, à perplexidade diante do que se perdeu, ao desejo de começar de novo ou, pelo menos, de entender como chegamos até aqui. E se, para a crítica, a poesia tem parecido escassa, sempre em falta, sistematicamente acuada diante dos acontecimentos, é possível dizer que "a poesia" é um nome adequado para designar a própria sensação crítica de falta e de acuamento. "A poesia" torna-se o nome daquele lugar discursivo em que a linguagem crítica obsessivamente manifesta um questionamento sobre a situação contemporânea, por meio do qual a crítica, de certo modo, numa espécie de monólogo dramático, lamenta a falta de grandes questões, de comprometimento, de negatividade compatível com a crise que fundamenta esse vazio. "A poesia", no discurso da crítica, é o topônimo da carência que perturba. Quero dizer com isso que o incômodo da crítica não é substancialmente diferente daquele atribuído à poesia; talvez seja uma extensão dele, uma extensão que considero necessária e comovente.

\section{Os estados da crítica}

Por que falar de poesia hoje? Quais são os imperativos que nos levam a retomar as razões da sua crise? Que tipo de relação se tem adotado com "a poesia"? Se "a poesia" é o lugar de uma fala que se estabelece em nome do poético, o que está em jogo é, também, um lugar de fundação do sentido, político ou outro, por meio de um apagamento ou de um recalque. 
Por isso, a crise da poesia deve ser pensada em paralelo com a crise que se atribui hoje à própria crítica. A "demissão da crítica", apontada por Paulo Franchetti ${ }^{18}$ diz respeito à incapacidade da reflexão brasileira que analisa a produção de literatura de formular criticamente o sentido e o valor dos objetos contemporâneos. ${ }^{19} \mathrm{O}$ autor aponta uma convivência estéril entre "o silêncio público" e a "maledicência privada" como horizonte de uma atividade crítica cujo resultado institucional é desastroso. A discussão está em aberto, mas constato que a opinião acerca das deficiências atuais da crítica literária reaparece na fala de notórios críticos ainda em atividade, de variadas tendências. Os impasses da reflexão contemporânea sobre o literário já vinham sendo apontados, por exemplo, por Leyla Perrone-Moisés, ${ }^{20}$ por razões específicas, ligadas à ascensão de critérios não literários nos estudos culturais e pós-estruturalistas, à perda do lastro tradicional do discurso crítico, que diz respeito à incapacidade de analisar o texto enquanto literário. Lembre-se que o próprio Silviano Santiago, no texto citado acima, ao mostrar a diferença de status cultural entre literatura e ciência, não coloca a crítica, a teoria, a "ciência" ou o pensamento da literatura entre os discursos prestigiados do seu tempo.

Embora o campo da reflexão sobre o literário, hoje, possa ser formulado de modo distinto da disciplinaridade tradicional (como o faz, por exemplo, a chamada "Teoria", partindo de saberes de diferente natureza, sem excluir a chamada "literariedade"), o que é notório é que tampouco a "crítica literária" está a salvo da crise aqui em foco. Ou seja, a ideia de que o discurso poético está em crise não se separa fundamentalmente, nas suas motivações, da crise do discurso crítico.

Como sujeito de uma fala que tem uma inserção na cultura, na mídia, no ensino, a crítica não escapa às injunções de seu tempo, aos impasses de sua situação: ela é interessada. Não é exclusivamente o sentido da literatura - e aqui, em especial, da poesia - que está em jogo. Acho que não é abusivo dizer que, quando a crítica se refere às deficiências da poesia contemporânea, está no fundo procurando elaborar as próprias demandas que ela, a crítica, teria por tarefa responder. A alegada ausência de grandes questões, ou de coerência de projeto, poderia também ser vista como uma descrição da situação da crítica, uma cobrança que a própria crítica se

18 FRANCHETTI, Paulo. A demissão da crítica. Sibila. São Paulo: Ateliê, n. 8-9, p. 25-40, 2005.

19 O autor denuncia "a anemia e o desinteresse que caracterizam a maior parte da produção brasileira que enfoca os textos literários do presente, incapaz de real enfrentamento com os objetos e problemas imediatos da cultura contemporânea e, principalmente, com a questảo do valor" (FRANCHETTI, Paulo, op. cit., p. 30). 20 PERRONE-MOYSÉS, Leyla. Altas literaturas. São Paulo: Companhia das Letras, 1998. 
faz, lucidamente, que os críticos se fazem e se dirigem, também a si mesmos, numa época em que as alternativas culturais parecem esvaziadas, em que se expressa certa melancolia e o sentimento do fim de uma época. ${ }^{21}$

Em outras palavras, a poesia não é a única vítima do "caos" do contemporâneo. A crítica também paga seu preço, e isso se manifesta na insistente demanda de sentido que ela tem dirigido ao poético. O que se chama hoje de "a poesia" me parece ser o nome instável, não exatamente deserdado ou errante, não exatamente plural e harmonioso, do lugar cultural que ocupamos. No corpo caótico dessa poesia, em seu relevo monótono, podemos distinguir não apenas incertezas quanto aos caminhos a seguir, mas toda uma topografia do "cansaço cultural", segundo a expressão de Mário de Andrade. Nesse sentido, "a poesia" não é exatamente aquilo que está em crise, mas é o nome da própria crise, daquilo que impõe e explicita a experiência do impasse e dá forma ao escrito, a qualquer forma de escrito, inclusive o da crítica literária. Mesmo quando procura abdicar do peso da crise, revogar o impulso sacrificial que a constitui modernamente; mesmo quando prefere navegar por mares mais tranquilos e previstos, numa época que convém ao impulso historicista designar como "pós-modernidade", a escrita não deixa de carregar essa experiência do impasse. Sintomaticamente, é na medida em que expõe a falta de controle sobre suas questões mais fundamentais (a eficiência da linguagem, o sentido político da cultura) que a crítica precisa a cada momento fazer a prova desse impasse que eu chamaria de "poético", que precisa mostrar-se inquieta e afetada por ele, recusando com isso o falatório crítico cotidiano e autocomplacente. Segundo Alcir Pécora, ${ }^{22}$ há algo que os escritores precisam admitir: "O inconfessável: escrever não é preciso". No modo retórico quase precioso do aforismo ou da moralidade, o crítico ataca não apenas a faixa "mediana" da literatura do presente, mas a sua própria ilusão de medianidade, diante da qual se perde a evidência, segundo ele, de que "não há nada de relevante sendo escrito". Quem escreve precisa justificar sua razão de escrever, de acrescentar mais páginas ao "mar de coisa escrita" do nosso tempo. Escrever não é preciso, numa época cuja crise é definida como "total falta de crise" A negatividade crítica

21 Uma análise específica desse "sentimento", desse modo de relação com a história, permitiria avaliá-lo de modo mais adequado; tal análise deveria incluir uma atenção com características socioculturais, com a tradição das ciências humanas e com a perspectiva que cada cultura tem sobre sua inserção na história mundial. Alguns dos traços a que refiro, entretanto, podem ser reconhecidos imediatamente como familiares, sobretudo na tradiçāo oriunda do pensamento europeu chamada, genericamente, "de esquerda".

22 PÉCORA, Alcir. O inconfessável: escrever nāo é preciso. Cronópios, 13 out. 2005. Disponível em: <http://www. cronopios.com.br/site/colunistas.asp?id_usuario=11\&id=657>. Acesso em: 06 mar. 2006. 
remete aqui à necessidade do esvaziamento de toda complacência retórica e institucional. O mais significativo é que, ao apresentar esse problema, o texto em questão se mostra como que afetado por ele, sendo levado a escalar o degrau da retórica da moralidade ou da "ficção crítica" (segundo um termo e um dispositivo caros ao autor). Tudo se passa como se a crítica, ao não encontrar elaboração convincente da crise pela poesia, se visse instada a fazer a prova da exigência que ela reclama da poesia, como se devesse fazer, ela mesma, a prova da crise poética. Independentemente da questão problemática dos cruzamentos entre texto "crítico" e texto "literário", assunto que sempre deu margem a uma série de mal-entendidos, podemos dizer, em todo caso, que a crise aqui designada como poética tem se tornado o lugar no qual a escrita é reconhecida dentro de uma nova situação cultural.

Não se trata, é claro, de esvaziar o conteúdo da demanda crítica por uma poesia ativa, corrosiva, ambiciosa, ideal propriamente moderno e humanista partilhado por intelectuais de tendências variadas dentro do espectro acadêmico. A cobrança aos poetas faz parte de um legítimo jogo de forças dentro do campo cultural, embora não lhes caiba nem apeteça a obrigatoriedade da resposta. No fundo, só existe liberdade de resposta quando se pode, de fato e de direito, não responder a uma pergunta, a uma solicitação. Por outro lado, como sugeri, é preciso reconhecer que, quando a crítica formula suas opiniões sobre a poesia ou dirige a ela suas demandas, está formulando também, por conta própria, e ao mesmo tempo, uma efetiva resposta para uma problemática que está além (ou aquém) do seu objeto. A questão que está em jogo parece ser, mais propriamente, antes do que o sentido ou o valor da poesia, a questão da postura a ser adotada diante do contemporâneo. Um dos sintomas disso é que os elementos apontados como problemas específicos da poesia contemporânea estão localizados, mais frequentemente, naquilo que emana da relação dos poetas com a tradição, com as instituições, com os outros poetas, enfim, na postura pública dos produtores de poesia, o que teria consequências previsíveis na esfera do poema.

Ao formular uma demanda de valor, a crítica expressa indiretamente uma inquietação quanto à atitude pública da escrita, inquietação legítima e necessária. Mas é preciso reconhecer que, ao fazê-lo publicamente, do modo como tem feito, sua enunciação constitui ao mesmo tempo o desejo de antecipar uma resposta, geralmente julgada "urgente" Nada mais significativo a esse respeito do que o apelo à resistência ("resistir à vulgarização do escrito"). ${ }^{23} \mathrm{O}$ imperativo da resistência, assim

23 Idem, ibidem. 
como a cobrança ou a expectativa de projeto cultural, de interesse pelas grandes questões do mundo são marcas do discurso da crítica que iluminam seu próprio desejo de refundação, de colocar-se fora do lugar onde estamos. Neste desejo, há, portanto, uma dimensão utópica dentro da qual a ética é entendida como aquilo que falta, que faz falta. Se assim for, não há como apontar o deslocamento da poesia, interrogá-la, pedir-lhe explicações, sem levar em conta esse imperativo, esse desejo ou esse interesse que diz respeito ao próprio olhar teórico e sua relação com a tradição que o constitui. Não há como falar de poesia, sem considerar historicamente nossa necessidade de crise. Só assim seria possível recolocar de outro modo a relação entre "crítica" e "poesia", discursos que separamos e opomos, mas que reagem às instabilidades da cultura de maneira semelhante e são, por assim dizer, cúmplices (não apenas neutros intérpretes) da situação e do devir histórico da literatura.

Marcos Siscar é professor do Departamento de Teoria Literária na Universidade Estadual de Campinas. 